\title{
MICROSTRUCTURAL CHANGES IN MA 760 DURING HIGH TEMPERATURE LOW CYCLE FATIGUE
}

\author{
A. Hynnä and V.-T. Kuokkala \\ Tampere University of Technology \\ Institute of Materials Science \\ P.O.Box 589, FIN-33101 Tampere, FINLAND
}

\begin{abstract}
$\underline{\text { Abstract }}$
The HTLCF properties and related microstructures of MA 760, a mechanically alloyed oxide dispersion strengthened Ni-base superalloy, were studied using specimens of two different grain orientations. The push-pull fatigue tests with total strain as a control parameter were conducted at two different strain rates, $\dot{\varepsilon}=0.005 \mathrm{~s}^{-1}$ and $\dot{\varepsilon}=0.0005 \mathrm{~s}^{-1}$, at the temperatures of $650^{\circ} \mathrm{C}$, $950{ }^{\circ} \mathrm{C}, 1000^{\circ} \mathrm{C}$ and $1050^{\circ} \mathrm{C}$. The fracture surfaces and the dislocation microstructures of the fatigued specimens were studied using optical microscopy, scanning electron microscopy (SEM) and analytical electron microscopy (AEM). In this paper, the changes in the microstructure of MA760 during strain cycling at high temperatures are reported and discussed.
\end{abstract}

\section{$\underline{\text { Introduction }}$}

To extend the good corrosion resistance and high strength values of conventional superalloys to even higher temperatures, new processing techniques and new types of microstructurc have becn developed during the past two decades. Dispersion strengthened (ODS) superalloys form one of such new materials groups, increasing the useful service temperature of, e.g., gas turbines, by almost hundred degrees (Ref. 1). ODS superalloys are produced by mechanically alloying the elementary constituents and a master alloy with pre-processed oxide powder (Ref. 2), followed by conventional processing and heat treatments, such as extrusion, hot rolling, recrystallization- and $\gamma$-precipitation heat treatments. The fine dispersion of stable, incoherent oxide particles formed during the mechanical alloying process is, to a large extent, responsible for the excellent high temperature mechanical properties of ODS- alloys by acting as strong obstacles to the mobile dislocations (Ref. 3). ODS Ni- base supcralloys are commonly strengthened also by coherent $\gamma^{\prime}$ precipitates which, however, start to lose their strengthening ability at around $1000{ }^{\circ} \mathrm{C}$, above which the dispersion strengthening becomes the dominant strengthening mechanism (Ref. 4).

The fatigue endurance of crystalline materials depends primarily on their ability to resist plastic deformation which, in turn, depends on the type, strength, distribution and stability of the obstacles that the mobile dislocations meet on the slip planes. In high temperature fatigue, the changes in the obstacle structure may be caused by both temperature as well as by cyclic deformation. For example, formation of dispersion poor areas may weaken the material substantially by allowing local plastic deformation which, under suitable conditions, may lead to the initiation and growth of fatigue cracks and finally to the failure of parts or components. The research results of microstructural changes during strain cycling at high temperatures are therefore of great importance when assessing the performance and reliability of high temperature materials in actual service conditions.

\section{Material and experimental techniques}

The mechanically alloyed Ni-base ODS superalloy MA 760 was produced in the form of bars with two different rectangular crosssections, SCS $(200 \mathrm{~mm} \times 600 \mathrm{~mm})$ and $\operatorname{LCS}(320 \mathrm{~mm} \times 950 \mathrm{~mm})$. Compositions of the delivered bars are given in Table $\mathrm{I}$. The final heat treatment of the SCS bar was $0.5 \mathrm{~h}$ solution treatment at $1100{ }^{\circ} \mathrm{C}$, furnace cooling with $60^{\circ} \mathrm{C} / \mathrm{h}$ to $600^{\circ} \mathrm{C}$, followed by uncontrolled furnace cooling. The heat treatment procedure for the LCS bar was the same with the exception that the solutioning temperature was $1120^{\circ} \mathrm{C}$.

Table I Compositions of the delivered bars

\begin{tabular}{|c|c|c|}
\hline Element & SCS, [wt-\%] & LCS, [wt-\%] \\
\hline $\mathrm{C}$ & 0.043 & 0.042 \\
\hline $\mathrm{Si}$ & 0.04 & 0.05 \\
\hline $\mathrm{Fe}$ & 1.02 & 1.04 \\
\hline $\mathrm{Cr}$ & 19.66 & 19.79 \\
\hline $\mathrm{Al}$ & 5.97 & 5.93 \\
\hline $\mathrm{Mo}$ & 1.92 & 1.96 \\
\hline $\mathrm{S}$ & 0.003 & 0.003 \\
\hline $\mathrm{Zr}$ & 0.14 & 0.14 \\
\hline $\mathrm{N}$ & 0.284 & 0.286 \\
\hline $\mathrm{W}$ & 3.5 & 3.5 \\
\hline $\mathrm{B}$ & $110 \mathrm{ppm}$ & $110 \mathrm{ppm}$ \\
\hline $\mathrm{P}$ & $<0.005$ & $<0.005$ \\
\hline $\mathrm{Ni}$ & $\mathrm{Bal}$ & $\mathrm{Bal}$. \\
\hline $\mathrm{Y}_{2} \mathrm{O}_{3}$ & 1.03 & 1.03 \\
\hline
\end{tabular}

Superalloys 2000
Edited by T.M. Pollock, R.D. Kissinger, R.R. Bowman,

K.A. Green, M. McLean, S. Olson, and J.J. Schirra

TMS (The Minerals, Metals \& Materials Society), 2000 
The SCS material was tested in the longitudinal (L) direction and the LCS material in the long-transverse (LT) direction. The orientation of the fatigue specimens relative to the grain orientation and the extrusion direction are shown in Figure 1.

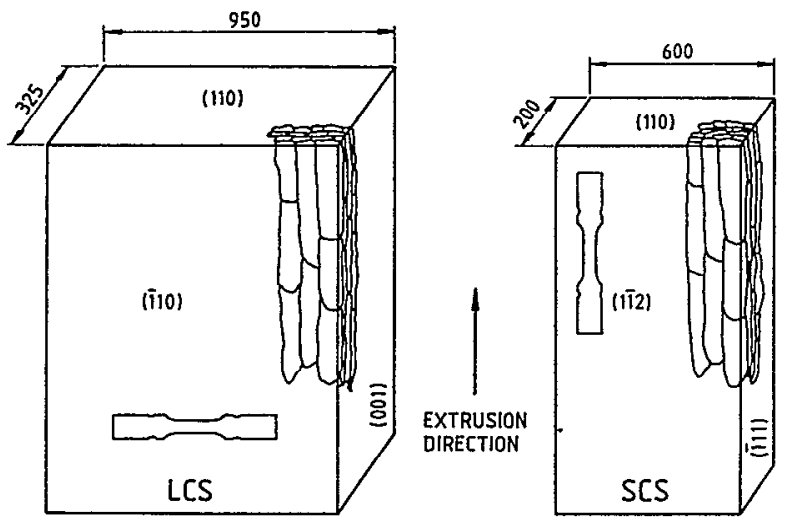

Figure 1. Cutting of the specimens from the extruded bars. Specimen gage length is $12 \mathrm{~mm}$ and diameter $7 \mathrm{~mm}$.
The total-strain controlled push-pull fatigue tests with a symmetrical triangular wave form $(R=-1)$ were conducted at four different temperatures in air using a strain rate of $0.5 \% \mathrm{~s}^{-1}$ (fast, F) or $0.05 \% \mathrm{~s}^{-1}$ (slow, S). Details of the testing conditions for each specimen can be found in Table II.

For microstructural studies of the reference material and the fatigued samples, optical microscopy, scanning electron microscopy and transmission electron microscopy were applied. Most fatigued specimens were cut parallel to the stress axis but in a few cases they were sectioned perpendicular to the applied stress. The reference material of both the SCS- and LCS-bars was investigated from both longitudinally and perpendicularly cut surfaces with respect to the extrusion axis.

A summary of the fatigue test parameters and mechanical test results is shown in Table $I$. The stress amplitudes $\sigma_{\max }, \sigma_{\min }$ and $\Delta \sigma / 2$ were measured from the cycle recorded at half life $\mathrm{N}_{\mathrm{f}} / 2$. As a failure criterion, a $20 \%$ stress drop was used. The interrupted tests mentioned in Table II were performed to study the dislocation structures free from the possible changes caused by cooling down under decreased stress. In these tests the specimens were cycled for 10 loops, straining was stopped at maximum total tensile strain of $0.5 \%$, and the cooling down was conducted under the tensile stress thus obtained.

Table IINumerical values recorded in the fatigue tests. Tests $28-31$ were interrupted after 10 cycles.

\begin{tabular}{|c|c|c|c|c|c|c|c|c|c|c|}
\hline $\begin{array}{l}\text { Test } \\
\text { No. }\end{array}$ & Bar ID & $\begin{array}{c}\mathrm{T} \\
{\left[{ }^{\circ} \mathrm{C}\right]}\end{array}$ & $\begin{array}{c}\dot{\varepsilon} \\
{\left[\% \mathrm{~s}^{-1}\right]}\end{array}$ & $\begin{array}{l}\Delta \varepsilon_{\mathrm{t}} \\
{[\%]}\end{array}$ & $\begin{array}{l}\Delta \varepsilon_{\mathrm{pl}} \\
{[\%]}\end{array}$ & $\begin{array}{l}\Delta \varepsilon_{\mathrm{e}} \\
{[\%]}\end{array}$ & $\begin{array}{c}\sigma_{\max } \\
{[\mathrm{MPa}]}\end{array}$ & $\underset{[\mathrm{MPa}]}{\sigma_{\min }}$ & $\begin{array}{c}\Delta \sigma / 2 \\
{[\mathrm{MPa}]}\end{array}$ & $\underset{\text { [cycl.] }}{\mathrm{N}_{f}}$ \\
\hline 1 & SCS & 650 & 0.5 & 1.0 & 0.1 & 0.9 & 850 & -950 & 900 & 792 \\
\hline 2 & SCS & 650 & 0.5 & 0.8 & 0.04 & 0.76 & 705 & -780 & 742.5 & 3925 \\
\hline 3 & SCS & 650 & 0.5 & 0.6 & 0.01 & 0.59 & 560 & -575 & 567.5 & 16320 \\
\hline 4 & SCS & 950 & 0.5 & 1.0 & 0.51 & 0.49 & 310 & -340 & 325 & 570 \\
\hline 5 & SCS & 950 & 0.5 & 0.8 & 0.35 & 0.45 & 275 & -305 & 290 & 960 \\
\hline 6 & SCS & 950 & 0.5 & 0.6 & 0.2 & 0.4 & 250 & -270 & 260 & 4575 \\
\hline 7 & SCS & 950 & 0.05 & 1.0 & 0.49 & 0.51 & 290 & -300 & 295 & 415 \\
\hline 8 & SCS & 950 & 0.05 & 0.8 & 0.34 & 0.46 & 270 & -285 & 277.5 & 880 \\
\hline 9 & SCS & 950 & 0.05 & 0.6 & 0.19 & 0.41 & 240 & -265 & 252.5 & 3945 \\
\hline 10 & SCS & 1050 & 0.5 & 0.8 & 0.55 & 0.25 & 160 & -180 & 170 & 395 \\
\hline 11 & SCS & 1050 & 0.5 & 0.8 & 0.55 & 0.25 & 160 & -180 & 170 & 595 \\
\hline 12 & SCS & 1050 & 0.5 & 0.6 & 0.35 & 0.25 & 170 & -195 & 182.5 & 1025 \\
\hline 13 & SCS & 1050 & 0.5 & 0.35 & 0.11 & 0.24 & 150 & -160 & 155 & 6925 \\
\hline 14 & SCS & 1050 & 0.5 & 0.25 & 0.01 & 0.24 & 160 & -180 & 170 & 67300 \\
\hline 15 & SCS & 1050 & 0.05 & 0.8 & 0.55 & 0.25 & 170 & -190 & 180 & 305 \\
\hline 16 & SCS & 1050 & 0.05 & 0.6 & 0.36 & 0.24 & 160 & -180 & 170 & 620 \\
\hline 17 & SCS & 1050 & 0.05 & 0.35 & 0.1 & 0.25 & 160 & -170 & 165 & 3350 \\
\hline 18 & $\mathrm{LCS}$ & 950 & 0.5 & 1.0 & 0.66 & 0.34 & 285 & -300 & 292.5 & 600 \\
\hline 19 & $\mathrm{LCS}$ & 950 & 0.5 & 0.6 & 0.3 & 0.3 & 250 & -275 & 262.5 & 2105 \\
\hline 20 & $\mathrm{LCS}$ & 950 & 0.5 & 0.45 & 0.15 & 0.3 & 240 & -260 & 250 & 6770 \\
\hline 21 & LCS & 1050 & 0.5 & 1.0 & 0.8 & 0.2 & 140 & -160 & 150 & 105 \\
\hline 22 & $\mathrm{LCS}$ & 1050 & 0.5 & 0.6 & 0.42 & 0.18 & 145 & -155 & 150 & 585 \\
\hline 23 & LCS & 1050 & 0.5 & 0.45 & 0.25 & 0.2 & 145 & -150 & 147.5 & 1125 \\
\hline 24 & $\mathrm{LCS}$ & 1050 & 0.05 & 1.0 & 0.79 & 0.21 & 140 & -145 & 142.5 & 110 \\
\hline 25 & LCS & 1050 & 0.05 & 0.6 & 0.4 & 0.2 & 135 & -155 & 145 & 580 \\
\hline 26 & LCS & 1050 & 0.05 & 0.45 & 0.26 & 0.19 & 145 & -150 & 147.5 & 1280 \\
\hline 27 & $\mathrm{SCS}$ & 1000 & 0.05 & 0.45 & 0.21 & 0.24 & 190 & -195 & 192.5 & 5980 \\
\hline 28 & $\mathrm{SCS}$ & 1000 & 0.05 & 0.45 & N/A & N/A & $\mathrm{N} / \mathrm{A}$ & $\mathrm{N} / \mathrm{A}$ & N/A & 10 (int.) \\
\hline 29 & SCS & 650 & 0.5 & 1.0 & $\mathrm{~N} / \mathrm{A}$ & N/A & N/A & N/A & N/A & 10 (int.) \\
\hline 30 & SCS & 950 & 0.5 & 1.0 & N/A & N/A & N/A & N/A & N/A & 10 (int.) \\
\hline 31 & $\mathrm{SCS}$ & 1050 & 0.5 & 1.0 & N/A & N/A & N/A & N/A & N/A & 10 (int.) \\
\hline
\end{tabular}




\section{$\underline{\text { Results and discussion }}$}

\section{Grain and boundary structures}

The grain structure in both the SCS- and LCS-bars is very coarse. In general, the grains are several centimeters long in the Ldirection and a few millimeters wide in both the ST- and LTdirections, as illustrated in Fig. 1. According to Martin and Tekin, (Ref. 5), most of the boundaries are of the low angle type.

The boundaries between adjacent grains are covered by agglomerated $\gamma^{\prime}$ giving rise to the contrast effect presented in Figure 2. Also discontinuous precipitation of chromium carbide along the boundaries is present. After cyclic straining at $650{ }^{\circ} \mathrm{C}$, no visible changes in the general appearance of the boundaries could be detected. At $950{ }^{\circ} \mathrm{C}$, the agglomerated $\gamma^{\prime}$ has, at least partly, disappeared. However, the most dramatic changes appear in the boundary structure of the samples fatigued at $1050^{\circ} \mathrm{C}$. This is due to the fact that $1050^{\circ} \mathrm{C}$ is above the $\gamma^{\prime}$ solidus of MA 760 , thus causing the dissolution of the agglomerated $\gamma^{\prime}$, leaving only a discontinuous carbide structure in the boundaries.

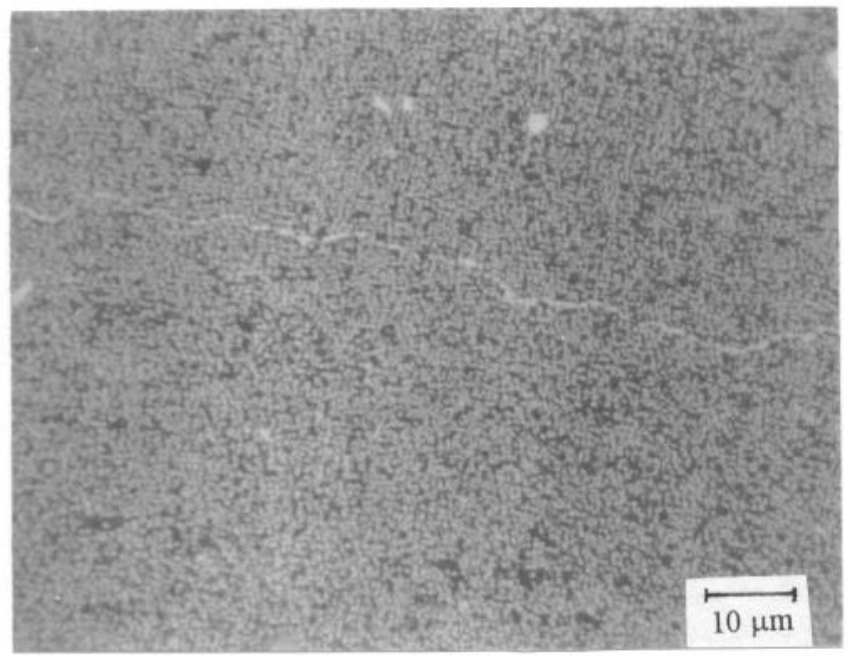

Figure 2. Optical micrograph of the longitudinal boundary in the SCS-bar reference sample.

The susceptibility of the boundary to the opening phenomenon was evident in the tests conducted at $1050{ }^{\circ} \mathrm{C}$, as illustrated in Figure 3. Although this phenomenon was observed in the fracture surfaces in all of the conducted tests, the opening of the boundaries is not so evident when studying the longitudinal sections of the lower temperature samples, especially in the case of tests at $650^{\circ} \mathrm{C}$. The susceptibility of the boundaries to opening is caused by oxidation effects, as stated in Ref. 6. The precipitated carbide particles at the boundaries make this opening even more pronounced. A clear evidence of oxidation is the $\gamma^{\prime}$ depleted zone beside the crack, which was observed also near the air exposed surface of the samples. This effect is more pronounced at higher temperatures and was not observed at $650^{\circ}$ $\mathrm{C}$ at all. The formation of these $\gamma^{\prime}$ depleted zones is caused by the diffusion of $\mathrm{Al}$ to form $\mathrm{Al}_{2} \mathrm{O}_{3}$ at the crack, leaving an insufficient amount of $\mathrm{Al}$ to form $\gamma^{\prime}$ in the vicinity of the crack. This phenomenon, as well as the accompanying formation of Kirkendall porosity, is illustrated in Figure 4. It should be pointed out that in the cracks observed inside the specimen which were not connected to the surface of the specimen, the formation of $\gamma^{\prime}$ depleted zones was not observed. The effects of transverse grain boundaries on the fatigue lives of LCS samples are discussed in an earlier paper (Ref. 15).

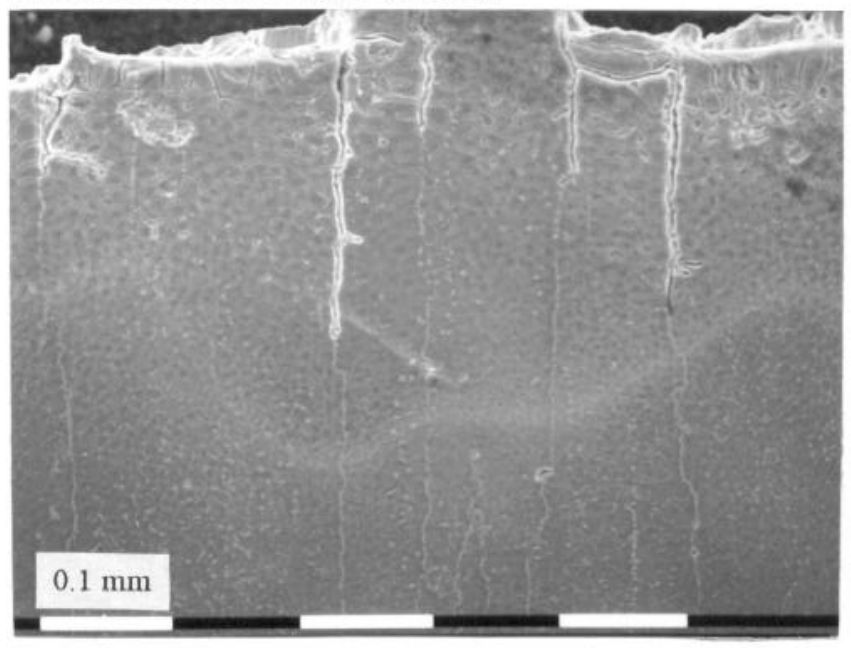

Figure 3. Opened longitudinal grain boundary starting from the fracture surface (sample 12).

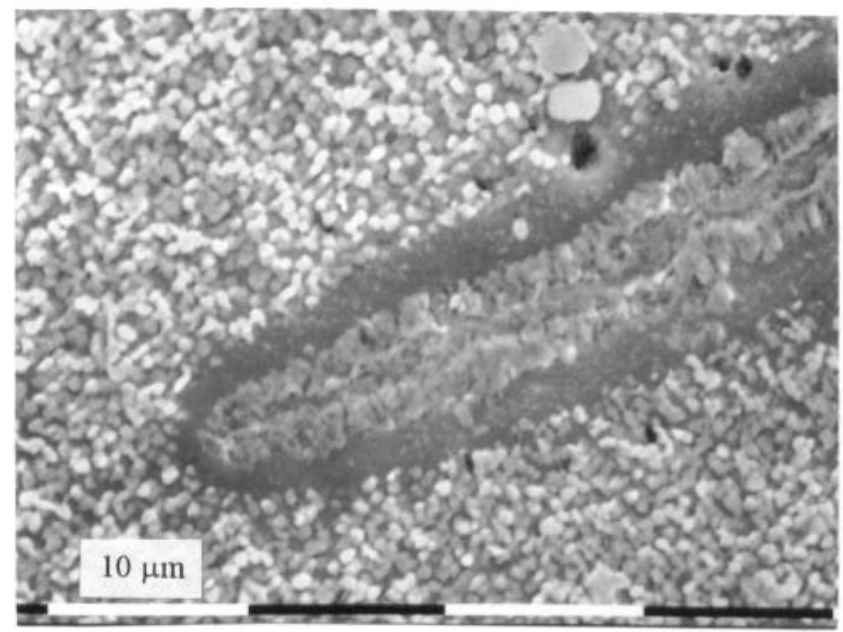

Figure 4. Tip of the opened grain boundary in sample 8 .

\section{$\underline{\gamma}$-structure}

In the reference materials, the $\gamma^{\prime}$ appeared as cuboidal precipitates, the cube sides oriented roughly along the extrusion direction. However, a considerable variation from grain to grain existed, especially in the small grains. The average side length of the precipitates was $0.5 \mu \mathrm{m}$. No large difference in the size and orientation of $\gamma^{\prime}$ between the SCS- and LCS-bars was observed.

In the samples fatigued at $650^{\circ} \mathrm{C}$, no observable changes in $\gamma^{\prime}$ size or shape could be detected, when compared with the reference material. After the exposure at $950^{\circ} \mathrm{C}$, the precipitates 
had clearly rounded, but their average size had not changed markedly; the average diameter was still measured to be $0.5 \mu \mathrm{m}$. However, considerable size variation is present with the diameter of the largest observed precipitates approaching $1.0 \mu \mathrm{m}$. This observation suggests that at these temperatures the process of Ostwald ripening, where small precipitates are dissolving and the larger ones are thus growing at the expense of smaller ones, is operative. The same process is also observed at $1000{ }^{\circ} \mathrm{C}$, although the average size of the precipitates was reduced to $0.4 \mu \mathrm{m}$ and the variation in sizes was larger than at $950{ }^{\circ} \mathrm{C}$. Finally, at $1050^{\circ} \mathrm{C}$, the precipitates seem to have more or less completely dissolved during the heating up period in each test. The small round precipitates found after testing are assumed to be due to the reprecipitation during cooling.

\section{Defect structure}

In general, MA 760 was found to be quite free of defects when compared with the previous versions of Ni-base MA alloys, e.g., MA 6000. However, several types of defects could be identified, such as small grains or groups of small grains, stringers of inclusions and individual inclusions. Generally, these defects were not critical when considering their ability to initiate propagating fatigue cracks.

In the same ways as the boundaries between large grains, the boundaries between large and small grains are covered by continuous agglomerated $\gamma^{\prime}$ film embedded with chromium carbide, the amount of which seems to be higher than in the boundaries between large grains. The orientation of $\gamma^{\prime}$ is very different in the small grains compared to the adjacent large grains, suggesting that these boundaries are of the high angle type. This observation seems to explain the increased susceptibility of the small grain boundaries to the boundary opening phenomenon as compared to the low angle boundaries. Also the shape of $\gamma^{\prime}$ inside small grains was sometimes, but not always, disturbed. This could be caused, e.g., by local variations in the element concentrations in the small grain area, since chemical composition has an effect on $\gamma^{\prime}$ morphology. In the case of disturbed $\gamma^{\prime}$ structures, possibly the heavy precipitation of carbides has, at least partly, been involved in the composition modification.

In addition to small grain areas, other types of defects were also observed. The most common of these defects were stringers of chromium carbide inclusions formed in the extrusion process. These inclusions were generally quite small, the average size being of the order of $3 \mu \mathrm{m}$. Also, a large variety of mainly individual $\mathrm{Cr}-, \mathrm{Al}$ - and $\mathrm{Ti}$-rich inclusions, containing small amounts of $\mathrm{Cu}, \mathrm{S}$ and $\mathrm{Si}$ were occasionally observed. All the elemental analyses of these inclusions were carried out using an EDS analyzer. The shapes of these types of defects varied largely from a blocky appearance to long elongated rods. Also the variation of their sizes was large, starting at $1 \mu \mathrm{m}$ and extending up to $0.5 \mathrm{~mm}$.

Generally all the defects, except stringers of chromium carbides, were found to initiate internal cracks which did not extend to the surface of the sample. These cracks, however, were secondary- or non-propagating and therefore they do not have an effect on the fatigue life. Two main types of damage processes were associated with these defects; pore formation at the boundaries of the defects and cracking of the inclusion and subsequent crack growth to the matrix.

\section{$\underline{\text { Pore formation }}$}

The pore formation in the fatigued samples falls into two main categories; pore formation ahead (on the boundary) or near a longitudinal crack and pore formation near the air exposed surface, including the fracture surface, of the sample. Concerning the latter category, it should be mentioned that there does not exist a general acceptance of the reasons for this phenomenon. In this research it was found that the amount of pores increased as a function of increasing temperature and increasing fatigue time. At $650{ }^{\circ} \mathrm{C}$, no pore formation was observed at all, and still at $950^{\circ} \mathrm{C}$ the capability of pores to form was very limited. Thus, the formation of pores is clearly restricted to the higher temperatures. A general observation in the fatigued samples was the concentration of stringers of pores in certain regions along the longitudinal direction. The pores lay in a surface region of $0.1 \mathrm{~mm}$ maximum depth, which decreases with decreasing fatigue time. In the longest tests, a tendency of the pore stringers to coalesce and to form longitudinal cracks was clearly observed. The pore size did not markedly depend on temperature or fatigue time, which only affected the number of the pore rich regions and the amount of individual pores inside these regions. The average pore size was of the order of $3 \mu \mathrm{m}$, that is, approximately the same size as the carbide particles in stringers. Very often, but not always, $\mathrm{Cr}$ was found to be present in the pores. Also Al-content, as measured by an EDS-analyzer, decreased towards the surface resulting in the formation of $\gamma^{\prime}$-depleted zones. The contents of the other alloying elements did not markedly vary as a function of depth. The appearance of the pore rich regions is presented in Figure 5. The above mentioned concerns only the L-samples. The picture changes dramatically when we look at the LT-samples. In this case the stringer formation is not observed at all and individual pores are lying completely in the $\gamma^{\prime}$ depleted zone of approximately $10 \mu \mathrm{m}$ in depth. The average pore diameter is approximately $1.5 \mu \mathrm{m}$.

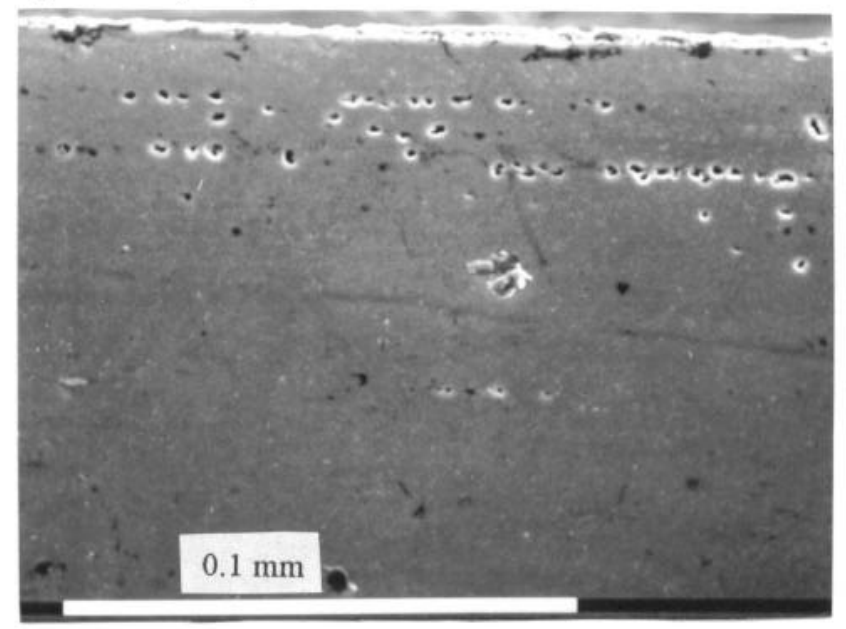

Figure 5. Pore formation in sample 14. Air exposed surface at the top. 
It is quite reasonable to assume that in spite of $\mathrm{Al}$ diffusion to the surface, the stringers of $\mathrm{Cr}$-carbides are also the reasons for the observed pore formation in the L-samples. The pores may be, at least partly, due to the specimen preparation, during which the carbide particles are pulled out of the matrix. Another possible source of the pull-out particles are the boundaries between the large grains or the boundaries around small grains, if suitably situated near the surface of the sample. The reasons for the pullout phenomenon are partly unclear, but interfacial decohesion between the carbide particles and the matrix takes place during deformation (Ref. 7). Also, the effects related to the cyclic straining are not alone responsible for the pore formation, because in the annealing tests of ODS alloys the phenomenon has also been observed (Ref. 8). In order to check whether adequate temperature is the only requirement for pore formation in MA 760 , a sample was heat treated for 144 hours at $1050{ }^{\circ} \mathrm{C}$. After the treatment no pore stringers were observed and therefore it is concluded that at the temperatures and fatigue times used in this study, cyclic straining is required to achieve sufficient loss of adherence of the boundary between the carbides and the matrix. In Ref. 8 it is stated that grain boundaries and scale/metal interface both act as a sink for vacancies. It is proposed that in this case the carbide/matrix interface at least partly acts as a sink for vacancies and therefore the interface looses its adherence to the matrix.

The pore formation associated with the grain boundary opening was also generally observed. The formation of pore strings takes place in the matrix beside the crack no further than $0.1 \mathrm{~mm}$ from the crack surface. In fact, this subcategory resembles almost identically the case discussed above and therefore the formation mechanisms of the pore strings can be suspected to arise from the same basis. It should be noted that in this case pore string formation at most $0.05 \mathrm{~mm}$ in front of the crack tip was also occasionally observed. These strings of pores were not at the boundary itself, rather they were in the same line than the pore strings observed beside the crack.

\section{TEM studies of the reference material}

Both longitudinal and transverse slices were prepared from the SCS- and LCS-material. No major differences could be detected either between the bars or between the slices. The microstructure was found to consist of approximately $50 \%$ cuboidal $\gamma^{\prime}$ with the average edge length of $500 \mathrm{~nm}$. To achieve a comprehensive picture of the size distribution of the dispersoids, over 200 randomly distributed dispersoid particles were analyzed. Generally the shape of the particles was almost round and the dispersoid diameters ranged from $2 \mathrm{~nm}$ to $120 \mathrm{~nm}$, the average being $35 \mathrm{~nm}$. With the exception of some clusters of dispersoids, the distribution was relatively homogeneous. The dispersoid structure was nearly the same both in $\gamma$ and $\gamma^{\prime}$. Microtwins, both in $\gamma$ and $\gamma^{\prime}$, with a width variation from $100 \mathrm{~nm}$ to $300 \mathrm{~nm}$ and a length variation from $700 \mathrm{~nm}$ to $2500 \mathrm{~nm}$ were frequently observed. The twin boundaries were often irregular due to the presence of dispersoid particles.

In the as-delivered condition, the alloy did not exhibit extensive dislocation structures. Generally the observed dislocations lay either at the $\gamma / \gamma^{\prime}$ boundaries or were pinned to dispersoid particles. Figure 6 presents a TEM-image of the microstructure of the as-delivered material.

Dispersion-dislocation interaction, usually referred to as backside pinning, is a frequent observation in many studies (e.g. Refs. 13 and 14). The phenomenon is illustrated in Figure 7, which shows a dislocation in a position where it has already surmounted a particle by climb (or pulled from the matrix to the interface) and adheres to the "departure side" of the dispersoid because of the attractive force between the dispersoid and the dislocation. The curvatures of the dislocation in the matrix and at the particle, showing the direction of the effective shear stress, have the same sign. An explanation for the attractive force is that a dislocation in the vicinity of an incoherent boundary surface can reduce a part of its strain field (and thus achieve a lower energy configuration) at high temperatures by diffusion. The dislocations also seem to be in intimate contact with the dispersoid and exhibit a sharp bend at the point of leaving the particle, which supports local climb theories.

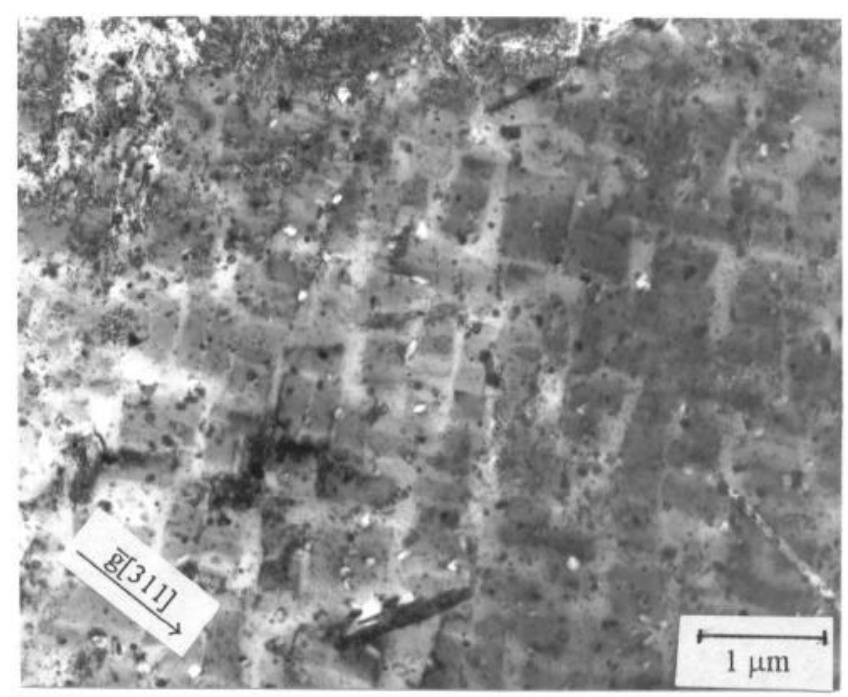

Figure 6. Microstructure of the SCS reference material.

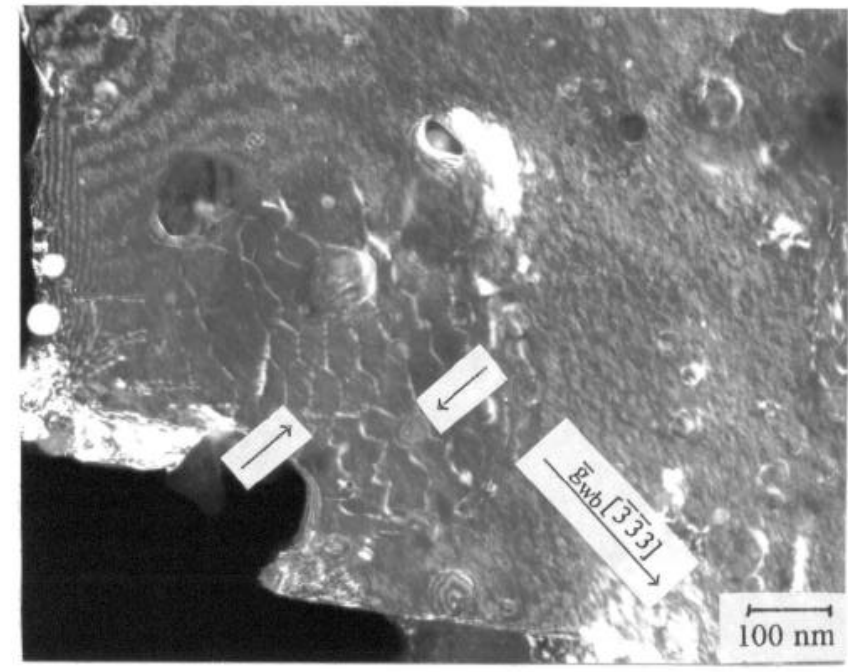

Figure 7. Weakbeam image from sample 26 illustrating the backside pinning phenomenon (arrows). 
Occasionally dispersion free areas were observed also in the asdelivered material. These defects originate from manufacturing processes and most probably they are milling defects. In the absence of pinning points for dislocations these defects have relatively low dislocation densities, which was also observed in the fatigued specimens.

\section{TEM studies of the $650^{\circ} \mathrm{C}$ tests}

In the tests conducted at $650^{\circ} \mathrm{C}$, the slip behavior of the alloy was rather homogeneous and, e.g., no signs of slip concentration to slip bands was observed. The most striking observation was that in $\gamma^{\prime}$ the dislocations were travelling in pairs. This, in turn, indicates that the operative deformation mechanism is $\gamma^{\prime}$ cutting. Generally the dislocations formed loosely spaced tangles. The back-side pinning was not observed as often as in the samples fatigued at higher temperatures, rather it seems that at this temperature the Orowan looping dominates over back-side pinning. When one hundred dislocation/dispersoid interactions were analyzed, it was found that $80 \%$ of the interactions were of the looping type in accordance with the observations in Ref. 9 for MA 754. The dislocations were more numerous in $\gamma^{\prime}$, although there were dislocations also at the $\gamma / \gamma^{\prime}$ interface and in $\gamma$.

No dramatic effects in the size or in the shape of $\gamma^{\prime}$ could be detected in the samples fatigued at $650^{\circ} \mathrm{C}$ when compared to the reference samples. This observation applies also to the dispersoid structure. Also in dislocation densities no marked differences could be detected. This seems quite natural because of the lack of cyclic hardening or softening, and therefore one expects a stable dislocation density to be generated during the initial cycles. In the interrupted test, the dislocation pairs cutting $\gamma^{\prime}$ were more readily observed, and generally the dislocations were not so curved as in test 3 . This suggests that obviously some changes do happen in the dislocation microstructure during the crack growth (effective stress drops as a function of crack length) and cooling down (effective stress is zero) periods. Especially the amount of dislocation pairs cutting $\gamma^{\prime}$ was lower in the test 3 than in the interrupted test. From these observations it can be concluded that the possible rearranging mechanisms (during the absence of effective stress) may be thermally activated glide or the climb of dislocations to the $\gamma / \gamma^{\prime}$ interfaces and the dislocation/dispersoid interaction reactions. The TEM-images from the samples fatigued at $650^{\circ} \mathrm{C}$ are presented in Figure 8.

\section{TEM studies of the $950^{\circ} \mathrm{C}$ tests}

The marked feature at $950{ }^{\circ} \mathrm{C}$ was the size and shape changes of $\gamma^{\prime}$; the shape had become a little more irregularly rounded, the average diameter varying in the $200 \mathrm{~nm}$ to $500 \mathrm{~nm}$ range. Obviously the misfit parameter had changed, because clear evidence of the formation of interfacial dislocations between $\gamma$ and $\gamma^{\prime}$ was detected. In the $\mathrm{Y}_{2} \mathrm{O}_{3}$ size distribution, no noticeable changes could be detected. However, the dispersoid particles were observed to be less homogeneously distributed, i.c., the amount of particle clusters, as well as the amount of areas of low particle concentrations, had increased markedly. The above mentioned concerns test 6 , whereas in the interrupted test the changes were not visible. These phenomena became more pronounced in test 27 conducted at $1000^{\circ} \mathrm{C}$, and this point will be discussed in detail in the next chapter.

When considering the dislocation interaction with the dispersion particles, roughly $80 \%$ of the dislocations were found to be attached to the particles. This observation is consistent with Ref. 9. Also $\gamma^{\prime}$ shearing by paired dislocations was evident. However, most of the dislocations appeared to have concentrated at the $\gamma / \gamma^{\prime}$ interfaces and in $\gamma$. As in the $650^{\circ} \mathrm{C}$ case, in the interrupted test the $\gamma^{\prime}$ cutting was more evident, indicating the necessity for cooling down under stress in order to avoid the relaxation phenomena. A typical microstructure of the samples fatigued at $950^{\circ} \mathrm{C}$ is presented in Figure 9.

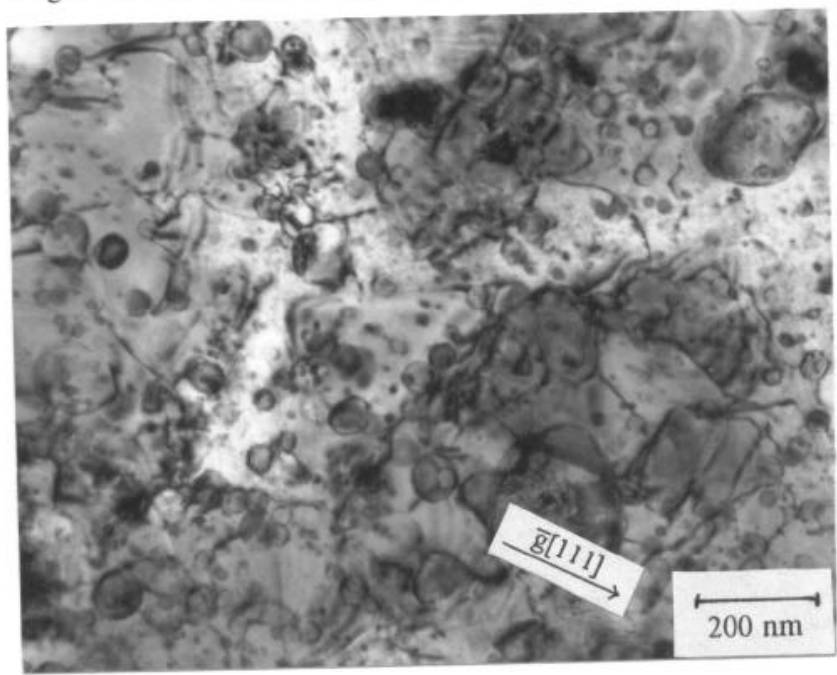

Figure 8. TEM-image from the sample 3 .

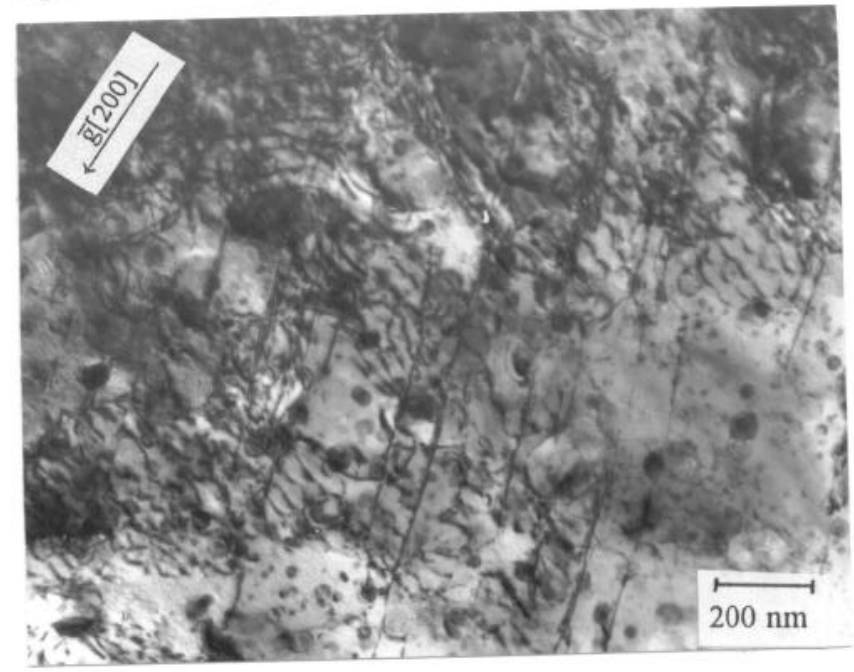

Figure 9. TEM-image from the sample 6.

\section{TEM studies of the $1000^{\circ} \mathrm{C}$ tests}

In test 27 conducted at $1000{ }^{\circ} \mathrm{C}$, the formation of dispersoid depleted zones in $\gamma^{\prime}$ (particle free zones, PFZ) was apparent, as presented in Figures 10 and 11. It was observed that the average size of the rounded $\gamma^{\prime}$ has increased to $750 \mathrm{~nm}$. At the same time 
the amount of $\gamma^{\prime}$ particles had decreased to $10 \mathrm{vol}-\%$ and the wavy contrast of the matrix had became clearly visible. This observation may be regarded as an indication of small $\gamma^{\prime}$ nuclei below the resolution limit all around the matrix (Ref. 10). These phenomena are a clear indication of Ostwald ripening, in which process some of the precipitates are growing at the expense of others in order to achieve energetically the most favorable structure.

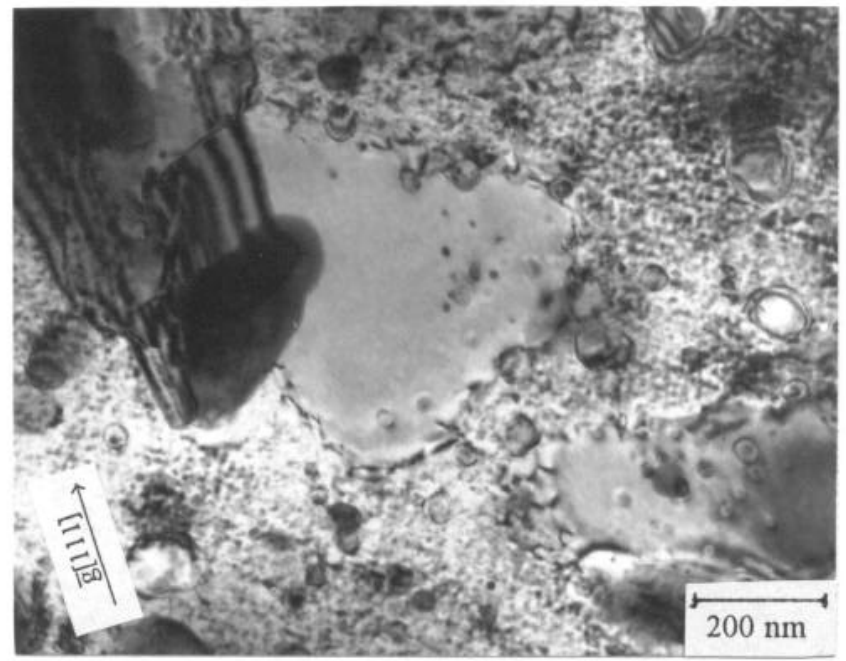

Figure 10. Particle free zone in sample 27.

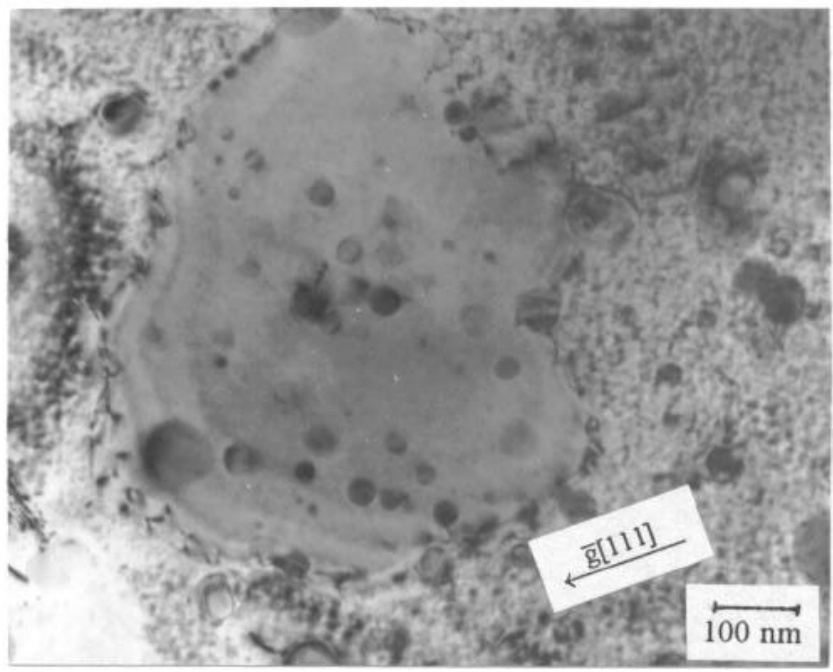

Figure 11. Particle free zone in sample 27.

A highly inhomogeneous distribution of the dispersoid particles is evident, as compared to the material in the as delivered condition. The same phenomenon can be observed inside the $\gamma^{\prime}$, as well as in the matrix. In fact, in the $\gamma^{\prime}$, where the dispersoids are more clearly visible, the particles seem to have arranged themselves along some loosely defined curves, as illustrated in Figure 11. In the following, it is supposed that the moving $\gamma / \gamma^{\prime}$ boundary exerts a dragging force on the dispersoid particles thus transporting them with the boundary and creating dispersoid free areas. Based on the latter, the explanation for the particles lying along curves (in fact, lying on surfaces), may be twofold. First, it is possible that the moving $\gamma / \gamma^{\prime}$ boundary can escape the dispersoid particles thus leaving them inside the growing precipitate. The second explanation is based on the assumption that the particles are showing the maximum dimension of some earlier precipitate, which has reached its maximum size and has started to dissolve. Considering the second alternative we have to suppose that the dragging force of the growing boundary is higher, when compared to the case of dissolutioning. Possibly both mechanisms operate; support for the second alternative is given in Figure 11, where the dotted line indicates a curve containing particles and curved in the 'wrong' direction, if supposed to be formed during the growth of the present precipitate.

Models for the interaction of second-phase particles with moving boundaries, especially with high angle grain boundaries are well established, both theoretically, e.g. in Ref. 11, and also experimentally (e.g. Ref. 12). When the moving boundary is interacting with particles, several phenomena can exist: 1) the boundary may be pinned by the particles, 2 ) the particles may be dragged by the boundary, 3 ) the particles may coarsen until the boundary can escape from them and 4) the boundary may migrate through the field of particles, if the driving force is sufficiently high. When considering phase transformations, the driving pressures $\mathrm{P}$ for boundary motion according to Ref. 11 are very high, lying in the $10^{7}-2 \times 10^{10} \mathrm{~N} / \mathrm{m}^{2}$ range. A boundary detachment will occur, if

$\mathrm{P} \geq \frac{3 \mathrm{f}_{\mathrm{v}} \psi}{2 \mathrm{r}}$

where $f_{v}=$ volume fraction of the particles, $\psi=$ boundary energy and $\mathrm{r}=$ particle radius.

In the case when the driving pressure is insufficient to detach the boundary from the particles, the boundary tends to drift slowly, dragging the particles with it. If we consider a particle moving with a velocity $\mathrm{v}$ under a force $\mathrm{F}_{\mathrm{p}}=\mathrm{A}_{\mathrm{p}} \mathrm{P}\left(\mathrm{A}_{\mathrm{p}}=\right.$ the mean area of boundary per particle), we can define to particle mobility $\mathrm{M}$ by

$\mathrm{v}=\mathrm{MF}_{\mathrm{p}}$

The mobility, depending on the temperature and the particle size, is determined by the relative rates of several processes illustrated in Figure 12. In this case it might be thought that the particle could advance as a rigid body through the solid by the diffusive motion of the surrounding matrix. Then its mobility would be determined by the fastest of the three alternative paths in the upper part of Figure 12:1) diffusion through the matrix, 2) diffusion along the interface and 3 ) diffusion through the particle itself, which in this case can be ruled out. Because of the high stability of the dispersoid, the diffusional processes involving the movement of the atoms of the particle (lower part of Figure 12), can also be excluded. According to Ref. 11, the crystallinity of the matrix imposes a constraint on the mobility of the particle. Removing a single matrix atom (black square, Figure 12) does not permit the remaining matrix atoms to rearrange so that the particle moves forward. The crystal lattice is still well defined and all the remaining atoms occupy defined positions. To 
overcome this problem, it was assumed that a dislocation-like defect climbs in the interface, but with a mobility which is limited by diffusion in the particle. Another possibility is the advance by the diffusive motion of a particle atom into the vacancy left by the removal of $(m)$. However, because of the high stability of the yttria particle, it seems probable that in this case the necessary diffusional processes to move the particle take place in the matrix or at the particle/matrix interface.

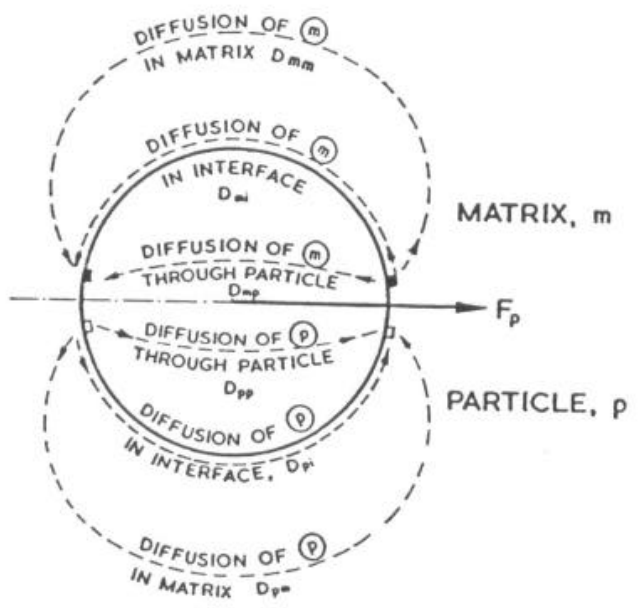

Figure 12. Diffusion paths (Ref. 11).

When analyzing more carefully the movement of the growing $\gamma^{\prime}$ boundary, it is clear that there is a net flux of $\gamma^{\prime}$-forming elements through the boundary and into the precipitate. Clearly there exists a dragging force on the boundaries, but unfortunately it is very difficult to establish any numerical values of the particle- or the boundary mobility itself because there are too many unknown factors involved in the process. Most important, it is not clear, whether a specific $\gamma^{\prime}$ precipitate has existed or has nucleated and grown from the beginning of the test. There is strong evidence that the case is not so, but the Ostwald ripening detected in this study is a dynamic process.

At $1000{ }^{\circ} \mathrm{C}$, the formation of well developed networks of interfacial $\gamma / \gamma^{\prime}$ dislocations was clearly observed as shown in Figure 13. The tendency for the formation of these dislocation networks is increased with decreasing coherency of the $\gamma^{\prime}$ and their function is to reduce the matrix/precipitate strain energy (Ref. 13). For this reason, these networks are not supposed to be damaging. According to Ref. 14, for the most efficient relief of misfit, the dislocations should be of edge character with Burgers vectors lying in the plane of the interface. This leads to a complicated three-dimensional model of misfit dislocations based exclusively on $a / 2\langle 110\rangle$ type dislocations. The network extends over the 14 faces of a tetrakaïdecahedron: the eight $\{111\}$ faces are covered with hexagonal grid patterns and the six $\{100\}$ faces with square and octagonal dislocation arrangements. It may be thought that these dislocation networks help the diffusion around the dispersoid particles at the moving $\gamma / \gamma^{\prime}$ interface by pipe diffusion, and with the aid of this mechanism the dispersion mobility is increased leading to the increased susceptibility for the PFZ formation.

\section{TEM studies of the $1050^{\circ} \mathrm{C}$ tests}

In the tests at $1050{ }^{\circ} \mathrm{C}$, the $\gamma^{\prime}$ had dissolved more or less completely during the heating up period. During the cooling down period, reprecipitation occurs. The precipitates are round with a diameter of approximately $50 \mathrm{~nm}$. Also in this case, as well as in the case of sample 30 , a general roughening of the background appears, as illustrated in Figure 14. This can be explained by assuming that most of the precipitates are smaller than the practical resolution limit of precipitates in TEM, approximately $5 \mathrm{~nm}$ (Ref. 10). This is supported by the observation that superlattice reflections of $\gamma^{\prime}$ are present in the diffraction pattern. The dispersoid structure resembles closely that detected in the tests conducted at $950{ }^{\circ} \mathrm{C}$, although the structure appears to be more homogeneous. The dislocations are totally pinned to the dispersoids forming tangled structures.

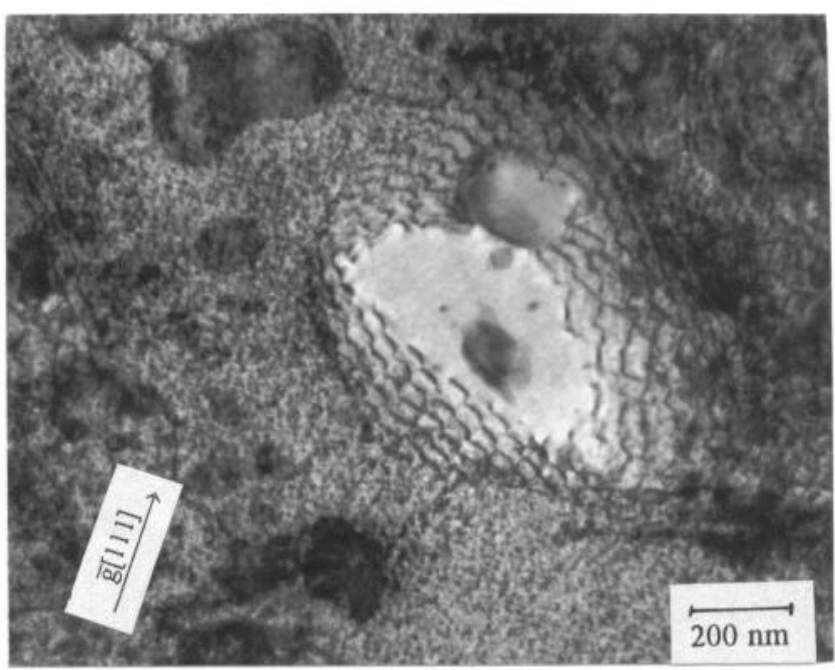

Figure 13. $\gamma / \gamma^{\prime}$ interfacial dislocations in sample 27.

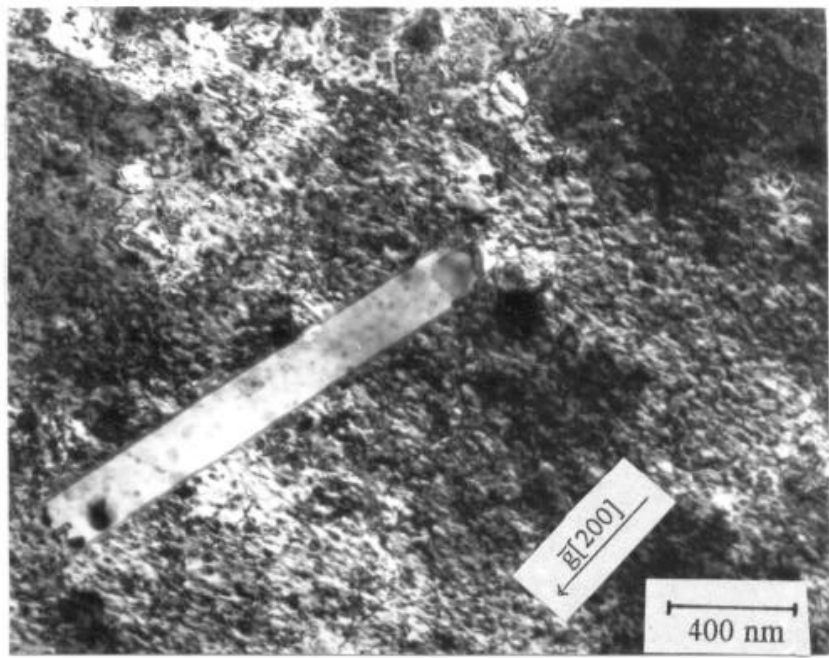

Figure 14. TEM-image from sample 31. 


\section{Summary of Results}

1. The $\gamma^{\prime}$ structure did not markedly change during the tests conducted at $650^{\circ} \mathrm{C}$, but at $950^{\circ} \mathrm{C}$ the precipitates became clearly rounded compared with the original cuboidal shape. At $1000{ }^{\circ} \mathrm{C}$, the process of Ostwald ripening was strongly operative and at $1050^{\circ} \mathrm{C}$, the $\gamma^{\prime}$ precipitates dissolved more or less completely, possibly already during the heating-up period.

2. At $650^{\circ} \mathrm{C}$ and $950^{\circ} \mathrm{C}$, cutting is the dominant dislocation interaction mechanism with $\gamma^{\prime}$. At $950^{\circ} \mathrm{C}$, the dislocations concentrated more into $\gamma$ and $\gamma / \gamma^{\prime}$ interfaces than into $\gamma^{\prime}$, which seems to be the case at $650^{\circ} \mathrm{C}$.

3. Departure side pinning of dislocations to dispersoid particles was a commonly detected phenomenon. However, at $650{ }^{\circ} \mathrm{C}$, Orowan bowing seems to dominate, the case being opposite at $950^{\circ} \mathrm{C}$ and at higher temperatures.

4. The formation of dispersoid free $\gamma^{\prime}$ areas was detected at $1000^{\circ} \mathrm{C}$. This phenomenon is caused by Ostwald ripening, where some of the precipitates grow at the expense of the others by the diffusion of the $\gamma^{\prime}$ forming elements through the $\gamma / \gamma^{\prime}$ boundaries. The boundaries exert a dragging force on the dispersoid particles, thus moving them with the boundary and creating dispersoid free areas.

\section{$\underline{\text { References }}$}

1. G. W. Meetham, "Superalloys in Gas Turbine Engines", Met. and Mat. Tech., 14(1982), 387-392.

2. J. S. Benjamin, "Mechanical Alloying", Sci. Am. 234(5)(1978), 40-48.

3. Y. Kaieda, "Trends in Development of Oxide-DispersionStrengthened Superalloys", Trans. Nat. Res. Inst. Metals, 28(3)(1986), 18-24.

4. M. J. Fleetwood, "Mechanical Alloying - The Development of Strong Alloys", Mat. Sci. Tech., 2(1986), 1176-1182.

5. J. W. Martin and A. Tekin, "COST 501-2, Project No. UK7, WP 1 - ODS", (Report No. 2; Jan. 89 - Jun. 90, Oxford University, Department of Materials, Oxford, UK, 1990).

6. A. Tekin and J. W. Martin, "Fatigue Crack Growth Behaviour of MA6000", Mat. Sci. Eng., (96)(1987), 41-49.

7. R. F. Decker and C. T. Sims, "The Metallurgy of NickelBase Alloys", in The Superalloys (eds. C. T. Sims and W. C. Hagel), (John Wiley \& Sons, New York, USA, 1972), 33-77.

8. A. H. Rosenstein, J. K. Tien and W. D. Nix, "Void Formation in INCONEL MA-754 by High Temperature Oxidation" Metall. Trans. A, (17A)(1986), 151-162.

9. R. S. Herrick, J. R. Weertman, R. Petkovic-Luton and M. J. Luton, "Dislocation/particle Interactions in an Oxide Dispersion Strengthened Alloy", Scripta Metall., (22)(1988), 1879-1884.

10. M. von Heimendahl, Electron Microscopy of Materials, (Academic Press, New York, 1980), 198-199.

11. M. F. Ashby, "The Influencc of Particles on Boundary Mobility", in Recrystallization and Grain Growth of Multi
Phase and Particle Containing_Materials, Proc. of the 1st Risø Int. Symp. on Metallurgy and Mat. Sci. (eds. N. Hansen, A. R. Jones, T. Leffers), (Risø Nat. Lab., Roskilde, Denmark, 1980), 325 - 336.

12. M. F. Ashby and R. M. A. Centamore, "The Dragging of Small Oxide Particles by Migrating Grain Boundaries in Copper", Acta Metall., (16)(1968), 1081-1092.

13. S. D. Antolovich, S. Liu and R. Baur, "Low Cycle Fatigue Behavior of René 80 at Elevated Temperature" Metall. Trans. A, (12A)(1981), 474-481.

14. A. Lasalmonie and J. L. Strudel, "Interfacial Dislocation Networks around $\gamma^{\prime}$ Precipitates in Nickel-Base Alloys", Phil. Mag., (32)(1975), 937-949.

15. A. Hynnä, V.-T. Kuokkala and P. Kettunen: "Crack Initiation Studies of MA760 During High Temperature Low Cycle Fatigue", Superalloys 1996, ed. R. D. Kissinger et al. (Warrendale PA: The Minerals, Metals \& Materials Society, 1996), 369-374. 